\title{
The evolving picture of standardisation and certification for process assessment
}

\author{
Terence P Rout \\ Software Quality Institute \\ Griffith University \\ Queensland, AUSTRALIA \\ T.Rout@griffith.edu.au
}

\begin{abstract}
The International Standard for Process Assessment, ISO/IEC 15504, has evolved over a period of almost twenty years, supported by extensive research and empirical study. A forthcoming revision of the Standard is intended to transform it from a single, multi-part standard to a set of related standards using a defined numeric range. This transformation will lead to an expanded range of application, and to a significantly more open standards framework. The revised requirements for the Standard envisage that it will address the assessment of other process characteristics beyond that of process capability, which has been the focus of attention to date. The scope also makes possible the extension of assessment to fields outside the ICT domain. Hand in hand with this evolution is a concentration on verification of conformance, with a view to formal certification of the results of assessments, whether in terms of profiles of Process Capability, or of Organizational Maturity. The proposed scope of work also incorporates a body of knowledge for process assessment, setting a standard for eventual certification of assessment professionals.
\end{abstract}

Keywords - process assessment; process improvement; certification

\section{INTRODUCTION}

The technique of process assessment has it origins in the work of Radice [1] and was further advanced through a series of methods developed at the Software Engineering Institute under the leadership of Humphrey $[2,3]$. A common thread throughout is the comparison of the actual performance of a process to some form of structured process model that serves as a yardstick, allowing the development of a "rating" of maturity or capability. With increasing use of assessment results in commercially sensitive areas, there was an increasing focus on formality in the assessment process. The increasing number of assessment approaches available and the increasing use of the technique in commercially-sensitive areas were the key motivating factors behind the development and acceptance of a proposal to develop an International Standard for software process assessment.

International standardisation activities relating to Process Assessment date back to 1991, when a Study Group was established to report on the Needs and Requirements for a Standard for Software Process Assessment [4]. Following the acceptance of the Study Group Report, the development of
ISO/IEC 15504 commenced in January 1993. The set of Working Drafts for ISO/IEC 15504 were developed by the SPICE Project [5] and entered the balloting process in June 2005. The initial version of the Standard was published in 1998 as an Interim Standard - a Technical Report Type 2 [6]. Work on the revision of this TR to a full International Standard started in October 1999. ISO/IEC 15504-2 was the first part to be completed and was published as an International Standard in October 2003 [7].

ISO/IEC 15504 currently comprises 7 published parts, and a further 3 parts under development. The current set of parts of the Standard is listed in Table 1. In line with the requirements for review of published standards five years after publication, a Study Group was established to determine the needs and requirements for revision of ISO/IEC 15504. The recommendations of this Study Group were adopted by the plenary meeting of JTC1/SC7 in Hyderabad, May 2009, and work on the revision has now commenced. The purpose of this paper is to set out the nature of the proposed revision, the rationale behind the proposal, and the potential impact of the work on standards and models for process assessment and improvement.

TABLE I. ISO/IEC 15504 PARTS AND STATUS

\begin{tabular}{|c|c|c|}
\hline Part & Title & Status \\
\hline Part 1 & Concepts and Vocabulary & Published \\
\hline Part 2 & Performing an Assessment & Published \\
\hline Part 3 & $\begin{array}{llll}\begin{array}{l}\text { Guidance } \\
\text { assessment }\end{array} & \text { on } & \text { performing } & \text { an } \\
\end{array}$ & Published \\
\hline Part 4 & $\begin{array}{l}\text { Guidance on use for process } \\
\text { improvement and process capability } \\
\text { determination }\end{array}$ & Published \\
\hline Part 5 & $\begin{array}{l}\text { An exemplar Process Assessment } \\
\text { Model }\end{array}$ & Published \\
\hline Part 6 & $\begin{array}{l}\text { An exemplar System Life Cycle } \\
\text { Process Assessment Model }\end{array}$ & $\begin{array}{l}\text { Published } \\
\text { (TR2) }\end{array}$ \\
\hline Part 7 & $\begin{array}{l}\text { Assessment of } \text { Organizational } \\
\text { Maturity }\end{array}$ & $\begin{array}{l}\text { Published } \\
\text { (TR2) }\end{array}$ \\
\hline Part 8 & $\begin{array}{l}\text { An exemplar assessment model for IT } \\
\text { service management }\end{array}$ & WD in development \\
\hline Part 9 & Target Process Profiles & $\begin{array}{l}\text { Circulated for DTR } \\
\text { Ballot }\end{array}$ \\
\hline Part 10 & Safety extensions & $\begin{array}{l}\text { WD circulated for } \\
\text { review }\end{array}$ \\
\hline
\end{tabular}




\section{CONCEPTUAL FRAMEWORK}

\section{A. Overview}

The technique of process assessment is essentially a measurement activity. The assessor examines an entity (the process) to determine the value to assign to a specified characteristic of the entity, through an examination of objective evidence collected from the performance of the process. To perform the assessment, it is necessary to have:

- A clear understanding of the nature of the process that is being assessed;

- A clear understanding of the process characteristic that is to be assessed;

- A scale for the clear representation of the value assigned to the characteristic; and

- A method for determining the value on the scale.

At this stage, the technique has been applied with success to the characteristic termed process capability, defined as "a characterization of the ability of a process to meet current or projected business goals" [7]. A defined ordinal scale for process capability has been established, and a method determined to assign to an implemented process, a value on this scale.

The determination of process capability is not, however, a direct assignment of a value; the Capability Level Rating as determined from process assessment is a composite measure derived from determining the extent of achievement of a set of defined Process Attributes. A process attribute is defined as "a measurable characteristic of process capability applicable to any process"; in the scale for Process Capability, which has 5 Capability Levels, there are 9 defined Process Attributes. A defined "rating scale" is used to assign a value for the extent of achievement of each Process Attribute, and from the assembled profile, the value of the Capability Level is derived [7].

Over the course of the SPICE Trials [8], [9], empirical data was collected from a significant number of assessments conducted using this Measurement Framework. It was determined that the scale was valid, and that the ratings determined - of both Process Attribute achievement, and of Capability Level - were valid and generally repeatable. The validity of Process Capability as a form of predictor of process performance was also supported [10].

It can be seen, then, that there are three core aspects of performance of process assessment that are of relevance and concern in considering the further evolution of the technique: the process models, containing the process definitions and indicators of evidence to be collected; the measurement framework, with the Capability Levels and Process Attributes; and the assessment process itself - the specification of the activities, resources and responsibilities for performing the assessment.

\section{B. Evolving concepts of Process Models}

Conventionally, in most relevant standards, a process is seen as a set of activities or tasks, converting inputs into outputs - see, for example, definitions in ISO/IEC 12207 [11]. This definition, however, is not generally suited for the assessment of process capability; there may be many different sets of distinct activities that achieve the same transformation. For the purpose of assessing process capability, it is of more value to explore the purpose for which the process is employed. Implementing a process results in the achievement of a number of observable outcomes, which together demonstrate achievement of the process purpose.

The purpose may be expressed in terms of the transformation of inputs into outputs; it may involve elaboration, evaluation, or even some change of state of the inputs. This approach is used to specify processes in a Process Reference Model; the model contains a set of processes described in terms of their purpose and the outcomes resulting from implementation.

The requirement that processes are described in terms of Process Purpose and Process Outcomes is a critical innovation in ISO/IEC 15504, and has since been formalized and more completely defined in ISO/IEC TR 24774 [12]. It provides for a form of definition that is independent of implementation concerns, and that focuses on the results of process performance.

The outcome of the decision in terms of the architecture of the International Standard was significant; it removed the Reference Model from the scope of the Standard, relying on the industry and the standards community to provide suitable reference models for use. The decision allowed for a multiplicity of both Reference Models and Assessment Models supporting process assessment, and resulted in a significant opening of the domain of the Standard. The basic principle is illustrated in Figure 1.

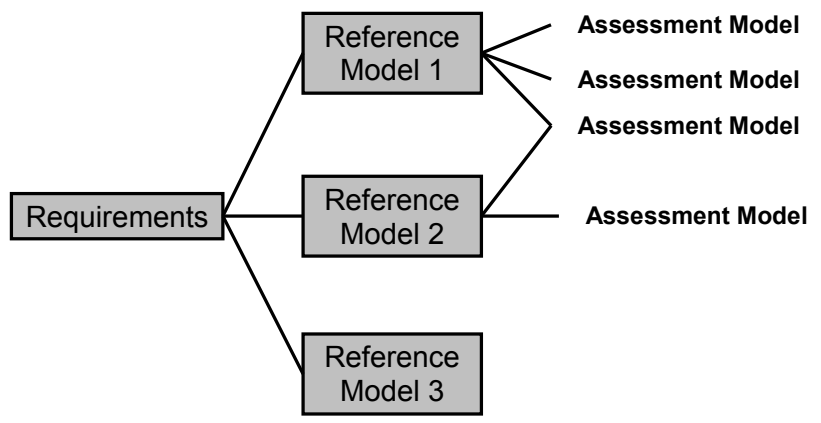

Figure 1. Reference and Assessment Models

This is now reflected in the fact that there are now three separate Process Assessment Models within the scope of ISO/IEC 15504, addressing Software Engineering, Systems Engineering and IT Service Management (refer Table 1). In addition, within the broader community, process reference and assessment models have been developed addressing component based development [13]; automotive software [14]; software for space systems [15]; and medical device software [16]. A model of limited scope, aimed specifically at supporting process improvement programmes in small and medium enterprises, has also been developed [17]. In addition, models 
have been developed applicable outside the scope of the IT industry, addressing issues of governance in financial organizations [18] and infrastructure for leadership [19]; some reports [20] have indicated potential for much more widespread application of the concept..

\section{Measurement frameworks}

In the original requirements for the development of the Standard [4], the focus was on the production of assessment results as profiles of process capability. The focus was on the definition of a framework and scale for evaluating the capability of processes - a "characterization of the ability of a process to meet current or projected business goals" [7]. The scale defined is formally a six-point ( 0 to 5$)$ ordinal scale; assignment of an implemented process as having demonstrated a specified level of capability uses a set of nine defined "Process Attributes" - one for Capability Level 1, two for each of Levels 2 to 5. The Capability Levels are listed, with a brief description, along with the Process Attributes, in Table II.

\section{TABLE II. CAPABILITY LEVElS AND PROCESS ATtRIBUTES}

\begin{tabular}{|c|c|c|}
\hline CL & Description & Process Attributes \\
\hline 0 & $\begin{array}{l}\text { Incomplete } \\
\text { The process is not } \\
\text { implemented, or fails to } \\
\text { achieve its process purpose. }\end{array}$ & (none) \\
\hline 1 & $\begin{array}{l}\text { Performed } \\
\text { The implemented process } \\
\text { achieves its process purpose. }\end{array}$ & Process Performance \\
\hline 2 & $\begin{array}{l}\text { Managed } \\
\text { The Performed process is now } \\
\text { implemented in a managed } \\
\text { fashion (planned, monitored and } \\
\text { adjusted) and its work products } \\
\text { are appropriately established, } \\
\text { controlled and maintained. }\end{array}$ & $\begin{array}{l}\text { Performance Management } \\
\text { Work Product Management }\end{array}$ \\
\hline 3 & $\begin{array}{l}\text { Established } \\
\text { The Managed process is now } \\
\text { implemented using a defined } \\
\text { process that is capable of } \\
\text { achieving its process outcomes. }\end{array}$ & $\begin{array}{l}\text { Process Definition } \\
\text { Process Deployment }\end{array}$ \\
\hline 4 & $\begin{array}{l}\text { Predictable } \\
\text { The Established process now } \\
\text { operates within defined limits to } \\
\text { achieve its process outcomes. }\end{array}$ & $\begin{array}{l}\text { Process Measurement } \\
\text { Process Control }\end{array}$ \\
\hline 5 & $\begin{array}{l}\text { Optimising } \\
\text { The Predictable process is } \\
\text { continuously improved to meet } \\
\text { relevant current and projected } \\
\text { business goals }\end{array}$ & $\begin{array}{l}\text { Process Change } \\
\text { Continuous Improvement }\end{array}$ \\
\hline
\end{tabular}

The scale as defined was specifically restricted to the evaluation of process capability. During the determination of requirements for the revision of ISO/IEC 15504, it was decided that the basic assessment approach could be applied to the evaluation of characteristics other than capability, and the revision of the Standard will make provision for this, through the definition of meta-level requirements for defining a scale for measuring process characteristics. At this stage, no firm candidates have been explicitly identified for this, but there have been suggestions that aspects of process integrity and trust could be addressed in this manner. The scale for process capability will be retained, as an established instance of the approach.

While the relevance of overall organizational implementation of processes was noted, the view within the Standards community was that issues of defining organizational scope impacted the reliability of overall organizational assessment. The initial focus was thus very strongly on defining a framework for measuring the capability of individual processes, based on objective evidence.

Over time, however, these views moderated. Analysis by Paulk et al [21] and Garcia [22], later adopted as a design strategy for the CMMI [23] established that a Maturity Level in a "Staged Representation" of a process model could be seen as defined through a specified profile of process capability.

Given significant interest from users of the Standard in the assessment of organizational maturity, the task of defining a suitable set of requirements was taken on, resulting in a new part of ISO/IEC 15504 - Part 7, Assessment of Organizational Maturity [24]. Part 7 defines a comprehensive approach to the assessment of organizational maturity, which is defined as "the extent to which an organization consistently implements processes within a defined scope that contributes to the achievement of its business goals (current or projected)" [23]. At this stage, it is uncertain whether the concept can be expanded to address organizational capabilities beyond that of product development; the ongoing application of the framework within the Standard will provide valuable experience with this.

In its present form, the Standard defines a measurement scale of 6 Maturity Levels ( 0 to 5 ), and sets out requirements for defining process profiles appropriate to each point on the scale. The basic structure of the scale is shown in Table III.

TABLE III. SCALE OF ORGANIZATIONAL MATURITY

\begin{tabular}{|c|l|}
\hline $\begin{array}{c}\text { Maturity } \\
\text { Level }\end{array}$ & \multicolumn{1}{c|}{ Characteristics } \\
\hline 0 & $\begin{array}{l}\text { The organization does not demonstrate effective } \\
\text { implementation of its processes that are fundamental to support } \\
\text { the organization's business. }\end{array}$ \\
\hline 1 & $\begin{array}{l}\text { The organization demonstrates achievement of the purpose of } \\
\text { the processes that are fundamental to support the organization's } \\
\text { business. }\end{array}$ \\
\hline 2 & $\begin{array}{l}\text { The organization demonstrates management of the processes } \\
\text { that are fundamental to support the organization's business. }\end{array}$ \\
\hline 3 & $\begin{array}{l}\text { The organization demonstrates effective definition and } \\
\text { deployment of the processes that are fundamental to support the } \\
\text { organization's business. }\end{array}$ \\
\hline 4 & $\begin{array}{l}\text { The organization demonstrates a quantitative understanding of } \\
\text { relevant processes that are fundamental to support the } \\
\text { organization's business goals, in order to establish consistent } \\
\text { and predictable performance. }\end{array}$ \\
\hline 5 & $\begin{array}{l}\text { The organization demonstrates the ability to change and adapt } \\
\text { the performance of the processes that are fundamental to } \\
\text { support the organization's business goals in a systematically } \\
\text { planned and predictable manner. }\end{array}$ \\
\hline
\end{tabular}

A key feature is the inclusion of a "Maturity Level 0 " in the scale; this distinguishes the approach from that taken in the CMMI [23], by defining a level of basic competence (ML 1) 
determined by the key business goals of the organization. There is an assumption that as organizations mature, they will "naturally" identify and correct weaknesses in their approach to their key business goals; this is not necessarily the case. The focus on institutionalisation can lead to "group think" that reinforces the use of poor practice. Where the practices are not conventionally exercised (in normal day-to-day work) their weakness may not be evident.

Considering the principles of a Continuous Representation of process capability leads to a new concept for Organizational Maturity: Level 1 as an achievement. On this view, Level 1 Maturity represents the situation where an organization has mastery of basic principles of those disciplines that are core to its business. Thus, the scale defines Maturity with respect to a specific domain; the "basic process set" is the set of processes addressing the primary value chain of the organization.

The framework for assessing Organizational Maturity incorporates requirements for constructing process models to support this aspect of assessment, based on the principle that a profile of process capability can be constructed that defines, for the domain of the model, each of the Levels of Organizational Maturity. An Organizational Maturity Model (OMM) is derived from a conformant Process Assessment Model (PAM). The generic structure of an OMM is illustrated in Figure 2.

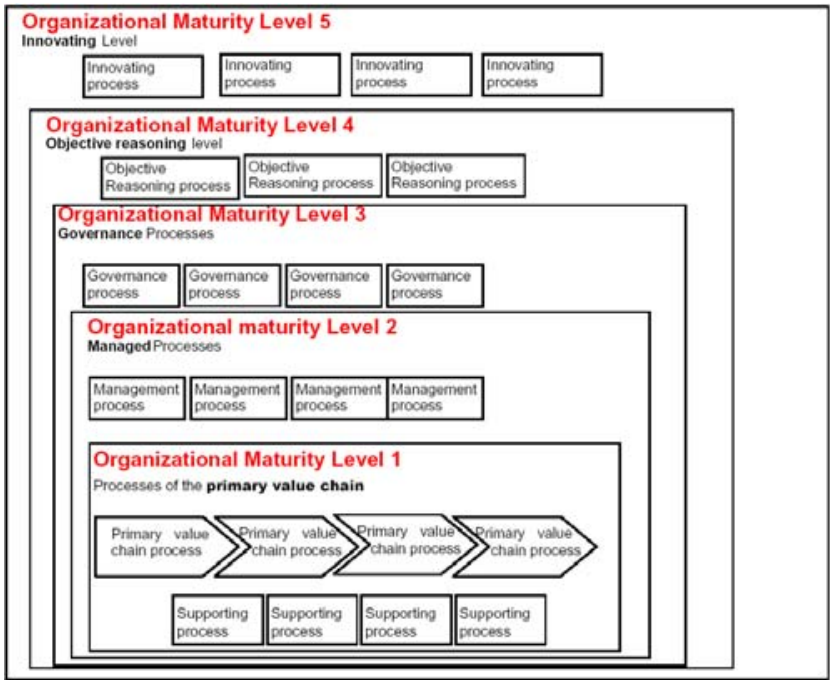

Figure 2. Structure of an Organizational Maturity Model

The OMM identifies from the PAM, firstly, a set of processes that are seen as "fundamental to support the organization's business"; this is termed the Basic Process Set, and defines the capabilities required to demonstrate achievement of CL1. For each Capability Level above 1, the OMM specifies a set of processes that enable the achievement of the additional characteristics associated with that Level. These are termed "extended process sets"; in general, within an individual OMM, these will be additive - i.e. the CL3 extended process set will include all of the CL2 set processes, with additional elements specific to CL3.

\section{The assessment process}

In its original concept, the intent of ISO/IEC 15504 was to provide a clearly defined set of requirements for the assessment process that could be implemented by a competent assessor in line with the assessment purpose. Given this, the original set of requirements do not impose any conditions for evidence coverage or extent of rigor in applying the process; rather, these issues are seen as requiring definition in the documented process applied in each individual assessment. This supported a wide application of process assessment, and encouraged conformant self-assessment; however, it also left unresolved issues of the degree of confidence that could be placed in the results of an assessment, and in the extent to which an assessment could be seen as representative of a specified organization.

With the extension of the framework to address the assessment of organizational maturity, the need arose for the issues of rigor and coverage to be formally addressed. These are issues that also arose in the evolution of the SCAMPI [25] assessment method for CMMI appraisals; the solutions adopted in Part 7 were similar in application and effect, but made use of the unique features of the Measurement Framework [7].

The scope of investigation of any assessment of organizational maturity has been another issue of major concern. The issue of the valid scope of an assessment rating was a key concern in the original discussions leading to the development of ISO/IEC 15504; considerations of the problem of "scope of application" were a principal issue in the decision to limit the scope of the Standard to the evaluation of process capability.

"An indication of the maturity and capability of an organisation is the extent to which its key processes are established. Does the organisation always do what it says it does? This can be assessed by examining the processes used by a sample of projects within an organisation. In general terms, the analysis of several projects will provide evidence for systematic strengths and weaknesses.

It is not generally possible to derive an organisational profile simply by summing or averaging the profiles of several projects. Such results may have no real meaning or validity. Organisational capability may be no better than the worst project.

On the other hand, it is possible to derive different organisational measures from observations across a number of projects. The analysis of processes across projects would give a measure of consistency, and therefore an indication of how institutionalised the process is. " [4]

For these reasons, the earliest drafts of ISO/IEC 15504 restricted the scope of ratings of process capability to individual process instances. It was not until late in the development of the initial ("Technical Report") version of the Standard that the scope was extended to cover the "organizational unit" within which the process was implemented. In all significant assessment approaches, the definition of the organizational scope is now seen as a critical issue, and its definition is an important phase in the assessment process. 
A related issue, commonly addressed in common with the definition of organizational scope, is the concern of ensuring that the data collected (and the organizational elements examined) are truly representative of the organizational unit that is being assessed. Particularly in a benchmarking / "certification" situation, the issue is significant. It is unlikely that any "foolproof" mechanism to prevent manipulation of data collection can be established, but method developers have established a variety of approaches to provide reasonable assurance.

In the development of ISO/IEC 15504-7 [24], the issue was addressed in two ways. In order to ensure a high degree of reliability, and to make certain that the assessment was representative of the organizational unit as a whole, requirements for data collection and process rating were substantially strengthened. Recognising, however, that this would have a significant impact on the resource requirements and cost of performing an assessment, an approach was adopted of defining three different classes of assessment, differing in levels of rigor. It is specified that only the high rigor classes can generate a rating of Organizational Maturity. The approach is similar to that employed with the Assessment Requirements for CMMI [26] and the different classes of SCAMPI appraisals [25].

The extension of the Standard set to address organizational maturity poses particular problems in any major revision or restructure of the suite. It provides additional requirements for performing assessment, and also for process models; and while it does not impact directly on the process ratings framework, it incorporates new requirements for performing rating in high maturity assessments that affect the same general topic.

\section{STRENGTHS AND WEAKNESSES}

The Standard for Process Assessment has been subject to intensive empirical study over the course of its development, through the medium of the SPICE Trials [8], [9], [27]. Key aspects of the assessment framework have been validated and improved, through three iterations of the document set. Among the key findings are the following:

- Confirmation of the consistency and predictive validity of the scale for measurement of process capability [28];

- Confirmation of the consistency of the four-point scale for rating achievement of the process attributes [29];

- Confirmation of the reliability of the assessment process, in terms of the level of inter-rater agreement [30];

- Confirmation of the efficiency of the assessment process, in terms of the resource requirements for assessment [31].

These positive factors were noted during the discussions of the Study Group, and the requirements that drove them were reaffirmed. Some areas of concern were also highlighted. The most significant issue was the need to find a mechanism within the standard set, to accommodate the growing demand for additional Process Reference and Process Assessment Models.
While it is quite possible for additional models to be introduced as Publicly Available Specifications, there is no clear mechanism to link these documents (through the standards numbering) to the parent standard. Conversion from a single, multi-part document (currently with ten parts) to a suite of related documents within a defined numerical range could address this problem.

The second major issue identified has arisen from the evolution of the standard set. In the original design, all requirements for performing assessment were contained in one part of the document set; however, with the development of the new requirements for assessment of organizational maturity (Part 7) [24], a new set of requirements, providing substantial added complexity, was added. There is then an urgent need for arriving at a concordance of Parts 2 and 7 to provide a single definitive normative document.

A third concern derives initially from the first problem identified - the proliferation of assessment models. With the growth in demand for such models, and the significant efforts being undertaken to develop them, it had become apparent to the community that the level of formalised guidance on this specific aspect - the definition and validation of process models - was inadequate. Consideration of this issue led to the realisation that overall, the level of guidance in the standards suite was no longer sufficient to meet the demands. In the transition from the Technical Report to the International Standard, the number of specific guidance documents was reduced from for to two; the community now realised that a much more substantial level of guidance, covering a wider range of topics, was required.

The strategy for the revision of the Standard, therefore, was based on the desire to retain the known strengths of the framework for assessment, established and confirmed through extensive empirical study, and address the issues and concerns identified by members of the standards community.

\section{A STRATEGY FOR REVISION}

The first part of ISO/IEC 15504 to be published was Part 2, in 2003. Under the ISO rules for review of Standards, revision of the standards set was to commence in 2008; accordingly, a study was launched within the Working Group in 2007, followed by a formal Study Group established within JTC1/SC7 in 2008. The Study Group report [32] contains a detailed review and extension of the requirements for the Standard on Process Assessment, and recommended significant changes in five areas:

- Overall structure of the document set;

- General requirements for assessment;

- Measurement framework;

- $\quad$ Process models;

- Level and content of guidance material.

\section{A. Structure of the Document Set}

The report proposes the transformation of the Standard for Process Assessment from a single, multi-part standard to a set 
of related standards within a defined range of numbers. The strategy is similar to that adopted for the revision of ISO/IEC 9126 and related standards to the SQUARE (ISO/IEC 25000) series [33]; the numbers ISO/IEC 33001 - 33099 have been reserved for standards within the Process Assessment domain.

Within the scope of work of the revision, there are additional concepts being incorporated into the framework, aimed at establishing an open and flexible approach to evaluating a variety of attributes of processes. In order to achieve this, separate sets of documents are envisaged, addressing the key elements of process assessment.

The view of process assessment embedded in the architecture of the standards set is based upon recognition that assessment is an activity concerned with the evaluation of various attributes of processes. Three key elements are seen in the framework: the assessment process itself; the definition of the entities to be assessed (processes); and the establishment of scales for evaluating various attributes of these entities (measurement frameworks).
The overall set of Standards also provides documents with different key functions; four principal groups can be identified, broadly corresponding to the classification of standards set out by Moore [34]. The groups are described in Table IV.

TABLE IV. Principal Groups of Standards

\begin{tabular}{|l|l|}
\hline \multicolumn{1}{|c|}{ Group } & \multicolumn{1}{|c|}{ Function } \\
\hline $\begin{array}{l}\text { Concepts \& } \\
\text { Terminology }\end{array}$ & $\begin{array}{l}\text { Provide definitions of key terms, and an overview of the } \\
\text { document set as a whole. }\end{array}$ \\
\hline $\begin{array}{l}\text { Normative } \\
\text { Components }\end{array}$ & $\begin{array}{l}\text { Provide requirements for performing assessments; for } \\
\text { constructing process models; and for defining } \\
\text { measurement frameworks. }\end{array}$ \\
\hline $\begin{array}{l}\text { Guides for } \\
\text { Application }\end{array}$ & $\begin{array}{l}\text { Guidance on applying the requirements, and on the use of } \\
\text { assessment in the principal contexts for use. }\end{array}$ \\
\hline $\begin{array}{l}\text { Defined } \\
\text { Elements }\end{array}$ & $\begin{array}{l}\text { Process Assessment Models and Process Models (Process Reference Models, } \\
\text { Maturity Models); Measurement Frameworks; and } \\
\text { Documented Assessment Processes. }\end{array}$ \\
\hline
\end{tabular}

(based on Moore [28])

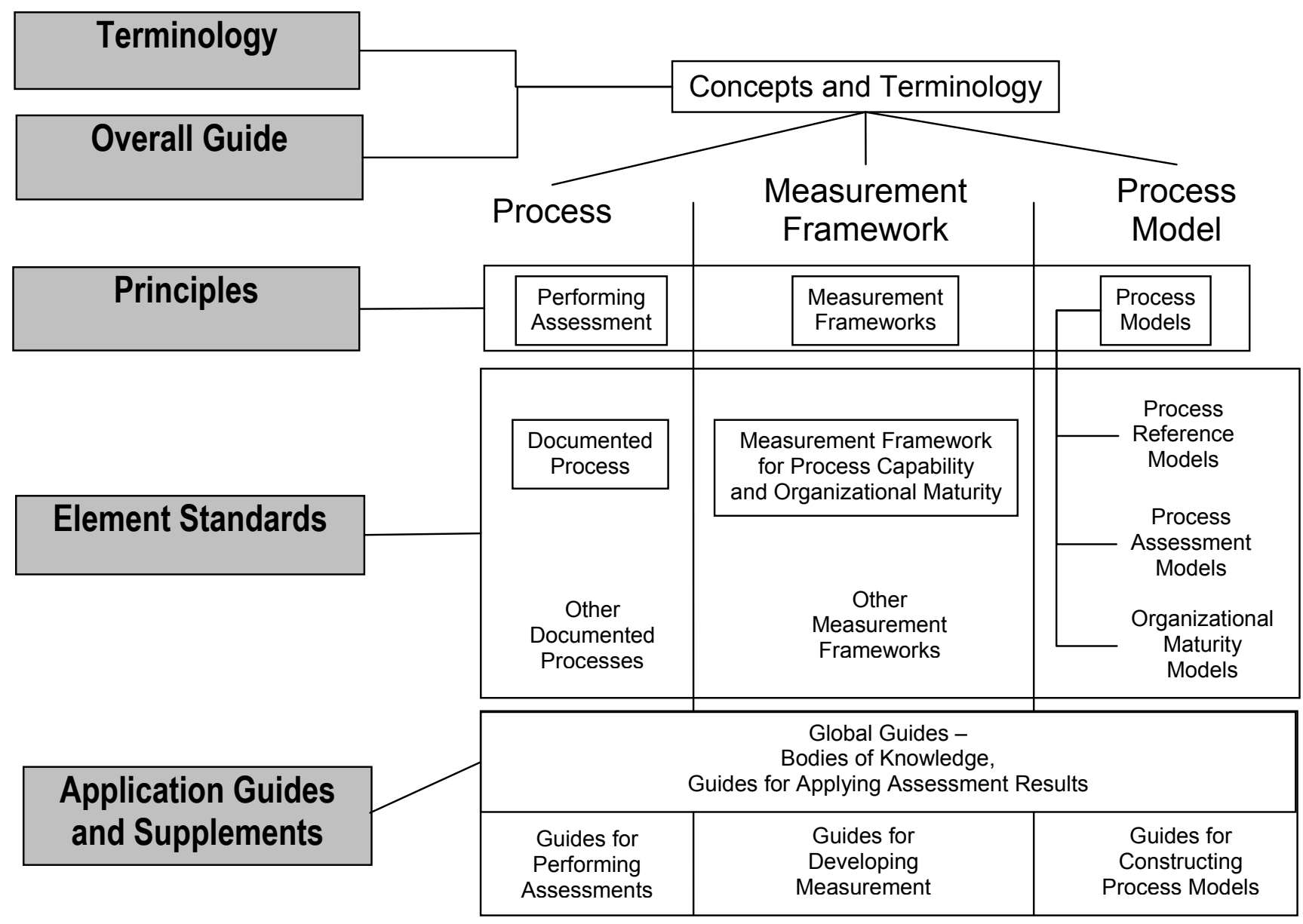

Figure 3. Structure of the Standards Suite 
Applying this rationale, the Study Group report provides an overall architecture for the set of standards, identifying seven groups of documents:

First Group:

This group of documents constitutes the core elements of the Standard, providing the basic requirements for constructing a framework for assessment, and the requirements for performing assessment. The standards in this group constitute the following elements in the framework:

- Concepts and Terminology

- General Requirements

Second Group

This group of documents provides guidance on the application of the set of Standards. There will be significant additional material addressing the construction of measurement frameworks and process models for assessment purposes.

\section{Third Group:}

This group is for conformant Measurement Frameworks. The group initially will contain only the measurement framework for process capability. Provision will be made for the definition of additional Measurement Frameworks, within the Standards Community and by external groups, and their inclusion in the framework.

\section{Fourth Group}

This group is for conformant Document Assessment Processes. Additional methods developed by external groups may be added through the PAS process.

\section{Fifth Group:}

This group is for documented Process Reference Models (PRM); the intention is to provide a placeholder for PRMs developed by external groups and endorsed as Publicly Available Specifications through the PAS process.

\section{Sixth Group:}

This group is for documented Process Assessment Models (PAM). Additional models developed by external groups may be added through the PAS process.

\section{Seventh Group}

This group is for documented Organizational Maturity Models (OMM). Where an OMM is developed within a single PAM, it may be included as an Annex to that PAM. Where an OMM is developed as a stand-alone document referencing one or more PAMs, it will be included in this Group.

The overall structure of the Standard Suite is summarized in Figure 3; the suite breaks down into three groups, based around the key components of process assessment - the Assessment Process, Measurement Frameworks, and the Process Models employed in assessment. At the present time, work has commenced on development of the key normative elements of the suite, while two of the key guidance documents are also in progress; the current status of the development effort is given in Table $\mathrm{V}$.
TABLE V. CURRENT STATUS - ISO/IEC 330XX

\begin{tabular}{|l|l|l|}
\hline Std No & Title & Status \\
\hline 33001 & Concepts and Terminology & WD \\
\hline 33002 & Requirements for Performing Assessment & WD \\
\hline 33003 & $\begin{array}{l}\text { Requirements for Process Measurement } \\
\text { Frameworks }\end{array}$ & WD \\
\hline 33004 & Requirements for Process Models & WD \\
\hline 33020 & $\begin{array}{l}\text { Measurement Framework for assessment of process } \\
\text { capability and organizational maturity }\end{array}$ & WD \\
\hline 33014 & Guide for process improvement & WD \\
\hline 33016 & Body of Knowledge for Process Assessment & NWI \\
\hline
\end{tabular}

A preliminary schedule for the standardization effort indicates that the initial phase of development will be completed in the second half of 2012. Additional guidance documents will be commenced once the critical technical issues in the normative components have been resolved, so that it is realistic to expect that the complete initial suite will be published by the end of 2013. Work to migrate the current set of Process Assessment Models to the new framework will probably commence late in 2011.

\section{B. General Requirements for Assessment}

The principal issue identified in relation to the general requirements for performing assessment is the need to provide an effective framework consistent with the need to ensure effective conformity assessment and certification of assessment results. The need for assessments to be able to integrate different domains of application, and to address organizations that have integrated management approaches across a variety of standards (e.g. ISO/IEC 20000, ISO/IEC 27000 and ISO 9001), was also highlighted.

It was noted that the requirements provided that assessment should be independent of the development or management approach; however, reports that there were difficulties in applying the assessment approach in agile environments had been put forward. It was recommended that the framework should address:

- different process views for different stakeholder perspectives; and

- different levels of assessment depending on the elements of a system or service that the process is applied to - e.g. product, service, project, organizational unit.

\section{Measurement Frameworks}

The existing Measurement Framework for evaluating process capability has been shown, through intensive empirical study, to be consistent and repeatable. However, there are several issues in its application that were highlighted as warranting consideration. The issue of application in agile environments was again noted, along with the need to revise the framework to better address integration of processes within 
organizations, and the application of multiple process models in a consistent assessment.

The need to review the existing "high maturity" levels in both the scales for Process Capability and for Organizational Maturity - CL 4 and 5, and ML 4 and 5 - was highlighted, and the need for additional empirical data from high-performance organizations was noted.

The key recommendation, however, has been to extend the overall standard to address the assessment of process characteristics other than capability. In order to achieve this, a set of "meta-level" requirements for the construction of Measurement Frameworks will be developed, and the existing Framework for assessment of process capability and organizational maturity will be separately developed as a instance of this concept.

\section{Process Models}

The major recommendations in respect to process models deal with the relationship between the different classes of model - reference models, assessment models and maturity models - and the extent to which models of one type can be integrated and used as the basis for "higher level" models.

The relationship between models employed in process assessment and the more prescriptive models often seen in source standards (ISO/IEC 12207, ISO/IEC 15288, ISO/IEC 20000-1) was also noted as requiring closer attention.

\section{E. Level and Content of Guidance}

The original SPICE Documents [5] provided significant guidance content over four parts of a nine document set; however, in the transition to a full International Standard, the level of guidance was significantly reduced. For this revision, the Study Group has recommended a significant expansion of the guidance content, divided into two classes: generic guidance relating to the conduct and use of the assessment technique; and specific guidance on the individual key components of the assessment framework. The concept is illustrated in Figure 3.

A notable feature is the proposal to define Bodies of Knowledge for Process Assessment, and also for Process Improvement. The Body of Knowledge for Process Assessment will provide more detailed guidance on the skills and competencies required for performing assessment. This is a particular focus with the emphasis on suitability for certification of conformance. There are several programs for the registration of assessors, claiming to provide assurance of the competence of registered individuals; however, there is no universally accepted benchmark for such competence.

\section{IMPACT OF THE REVISION}

It is anticipated that the impact of this strategy for revision of the Standard will be twofold. On the one hand, it will further extend the scope of the technique of process assessment, taking it beyond the evaluation of "process capability" to explore the assessment of other characteristics of processes, providing a quantitative insight into multiple aspects of process performance. On the other hand, the approach is specifically designed to encourage interest groups within the wider professional community to migrate process models, measurement frameworks and documented assessment processes into the international standards arena, utilizing the proven approach of Publicly Available Specifications.

The expansion of guidance material is also expected to impact on the use and application of the set of standards. The level of guidance available for constructing process models in the existing standard is not adequate, and this has been reflected in the problems encountered by interest groups in attempts to develop conformant models; the availability of more detailed and complete guidance for this and other aspects of assessment should encourage wider adoption of conformant approaches. The definition of relevant Bodies of Knowledge, intended as key new guidance components, will also support more effective performance of assessment and will put in place an important pre-requisite for broader professionalization of the work of assessment.

\section{A FRAMEWORK FOR CERTIFICATION}

As the Standard has evolved, it has trended towards a more formal and rigorous approach to process assessment; and this has led inevitably to a focus on verification of conformity, and on the certification of both conformant artifacts and the results of assessment. In the initial stages of the project, there was an overall view that certification of assessment results was not seen as desirable; in fact, Clause 1 of the Technical Report declared that:

"ISO/IEC TR 15504 is not intended to be used in any scheme for the certification / registration of the process capability of an organization." [6]

The declaration was omitted in the full International Standard [7], and some National Bodies developed approaches for certification of both individuals performing assessment, and or the results of assessment.

With the worldwide take up of ISO/IEC 15504, requirements to meet target process capability levels and organizational maturity levels were increasingly being made in contracts. There was seen to be a need for a scheme whereby assessments could result in the issue of not only an assessment report but also a certificate of process capability and/or organizational maturity following the completion of an assessment. In order to facilitate this, work was commenced on the development of a Standard addressing the application of conformity assessment methodology to process capability and organizational maturity. This work, when completed, will be published as ISO/IEC 29169 [35].

A series of pilot assessments providing certification of Organizational Maturity, based on ISO/IEC 15504-5 and on the Automotive SPICE assessment model, have been conducted [36], and the results have confirmed the feasibility of the scheme.

The eventual framework for certification will address verification of conformity for all artifacts specified in the Standards suite, including Process Models of all forms (PRM, PAM, OMM); Measurement Frameworks; and documented 
Assessment Processes. In addition, and more specifically, it will provide for the issue of certificates by appropriately registered organizations that a process assessment conformant with the requirements of the Standard has been performed, and certifying the results in terms of Profiles of Process Capability or Organizational Maturity Level.

It is likely also, with the definition of a Body of Knowledge for Process Assessment specified as an output of the project [32], that schemes for certification of individuals as competent to conduct assessments of different types will emerge, based on existing training and registration schemes.

The experiences of the international community with certification of Quality Management Systems provide a good insight into both the benefits and the potential problems associated with this approach; the track record of the standards group to date indicates a strong chance of favorable outcomes.

\section{SUMMARY AND CONCLUSIONS}

The development of the Standard for Process Assessment has been a landmark project, both in terms of the conduct of the work and the impact of the standard on the state of knowledge in the domain. From the beginning the project explicitly included strategies for validation of the elements of the Standard, and also for transition of the technology into use. At this juncture - nearly 20 years after the first tentative steps the move towards the next generation of the Standard is under way.

The vision for this revision further extends the scope of the technique of process assessment. This has been the most significant achievement of the Standard; from an initial narrow focus on the processes of the software life cycle, the Standard within its own scope addresses assessment of software, systems and IT service management processes. Outside the standards community, its application is already spread across numerous domains, including several that are outside the scope of Information Technology.

The development and evolution of the standard has been accompanied by parallel efforts in research and development that have significantly expanded the state of knowledge [27]. It seems likely that this tradition will continue, providing fresh insights into process modeling, process assessment and process improvement.

\section{ACKNOWLEDGMENTS}

The active participation of my colleagues on the Study Group for Revision of ISO/IEC 15504, and those in the wider WG10 community, is gratefully acknowledged; particular credit is due to Alec Dorling, Convenor of SC7/WG10 since its establishment.

\section{REFERENCES}

[1] R.A. Radice, J.T. Harding, P.E. Munnis and R.W. Phillips, "A Programming Process Study", IBM Systems J., Vol 24, No 2, 1985, pp 91-101.

[2] Watts S. Humphrey "Characterizing the Software Process: A Maturity Framework", IEEE Software, March 1988 pp. 73-79
[3] Olson, T.G., Humphrey, W.S., and Kitson, D. 1989. Conducting SEIAssisted Software Process Assessments. Software Engineering Institute: Technical Report CMU/SEI-89-TR-7

[4] ISO/IEC JTC1/SC7 SC7 N944R, Report of the Study Group on the Needs and Requirements for a Standard for Software Process Assessment, June 1992.

[5] SPICE Project, Software Process Assessment, Parts 1 - 9, June 1995.

[6] ISO/IEC TR 15504: 1998, Information technology - Software process assessment, Parts 1 - 9.

[7] ISO/IEC 15504:2003 - 2006 - Information technology - Process assessment, Parts 1-5.

[8] Maclennan, F., G. Ostrolenk. 1995. The SPICE trials: Validating the framework. Software Process: Improvement and Practice 1(1), 48-55.

[9] Jung, Ho-Won, Robin Hunter, Dennis Goldenson and Khaled El-Emam, "Findings from Phase 2 of the SPICE Trials", Softw Proc Improve Pract. 6: 205-242 (2001).

[10] Rout, T.P., "The SPICE Project: Past, Present and Future", invited keynote address, Software Process '96, Brighton, December 1996.

[11] ISO/IEC 12207:1995, Information Technology - Software Life Cycle Processes, Amd 1/2:2000

[12] ISO/IEC TR 24774: 2007, Software and systems engineering -- Life cycle management -- Guidelines for process description

[13] Henderson-Sellers, B., J.Bohling and T.Rout, "Creating the OOSPICE Model Architecture: A Case of Reuse". SPICE 2002, Venice, Italy, March 2002.

[14] Hoermann, K., Mueller, M., Dittmann, L., and Zimmer, J. 2008 Automotive SPICE in Practice: Surviving Implementation and Assessment. 1st. Rocky Nook.

[15] Cass, Ann, Christian Völcker, Rafik Ouared, Alec Dorling, Lothar Winzer, Juan María Carranza, "SPICE for SPACE trials, risk analysis, and process improvement", Softw Proc Improve Pract. 9, 13-21, 2004

[16] McCaffery, F. "A software process development, assessment and improvement framework for the medical device industry". SPICE 2004, Lisbon, Portugal, April 2004.

[17] T. P. Rout, A. Tuffley, B. Cahill, and B. Hodgen, "The rapid assessment of software process capability," presented at SPICE 2000 - 1st International Conference on Software Process Improvement and Capability dEtermination, Limerick,2000.

[18] Bernard, C., D.Hagen, P.Maar, D.Reinard, B.Di Renzo, M.Hillairet M.Picard, A.Rifaut, "Operational Risk Management in Financial Institutions: Process Assessment in Concordance with Basel II", SPICE 2005, Klagenfurt, Austria, May 2005.

[19] Tuffley, D., " Evolving a Process Reference Model for the Leadership of Integrated Virtual Teams", SPICE 2008, Nuremberg, Germany, May 2008.

[20] Coletta, Antonio, "An industrial experience in assessing the capability of non-software processes using ISO/IEC 15504", Softw Proc Improve Pract. 12, 315-319, 2007

[21] Paulk, M.C., M.D.Konrad, and S.M.Garcia, "CMM Versus SPICE Architectures", IEEE Software Process Newsletter, No. 3, pp. 7-11, 1995.

[22] Garcia, SM, Evolving improvement paradigms: capability maturity models and ISO/IEC 15504 (PDTR), Softw Proc Improve Pract. 3, 4758 (1997)

[23] Chrissis, M.B, M.Konrad and S.Schrum, CMMI: Guidelines for Process Improvement and Product Improvement, Boston: Addison-Wesley, 2003.

[24] ISO/IEC 15504-7:2008, Information technology - Process assessment Part 7: Assessment of Organizational Maturity

[25] SCAMPI Upgrade Team. 2006. Standard CMMI® Appraisal Method for Process Improvement $\left(\mathrm{SCAMPI}^{\mathrm{SM}}\right) \mathrm{A}$, Version 1.2: Method Definition Document. Software Engineering Institute: Handbook CMU/SEI-2006-HB-002.

[26] CMMI Product Team, "Appraisal Requirements for CMMI Version 1.1 (ARC V1.1)", Technical Report CMU/SEI-2001-TR-034, December 2001 . 
[27] Rout, T.P., K.El-Emam, M.Fusani, D.Goldenson and H.-W. Jung, "SPICE in retrospect: Developing a standard for process assessment. $J$. Systems Softw., 80, 1483-1493 (2007)

[28] El-Emam, K., A. Birk. 2000. Validating the ISO/IEC measure of software requirement analysis process capability. IEEE Trans. on Software Engineering 26(6), 541-566.

[29] H-W Jung, R Hunter, 2003. Evaluating the SPICE rating scale with regard to the internal consistency of capability measures, Software Process: Improvement and Practice, 8(3), 169-178.

[30] Simon, J.-M., K. El-Emam, S. Rousseau, E. Jacquet, F. Babey. 1997. The reliability of ISO/IEC PDTR 15504 assessments. Software Process: Improvement and Practice 3(3), 177-188.

[31] El-Emam, K., J.-M Simon, S. Rousseau, E. Jacquet. 1998. Cost implications of interrater agreement for software process assessment. In Proceedings of the 5th International Symposium on Software Metrics, $38-51$
[32] ISO/IEC JTC1/SC7, Report of the Study Group on Revision of ISO/IEC 15504. 07N4352, 2009.

[33] W. Suryn, A. Abran, and A. April, "ISO/IEC SQuaRE. the second generation of standards for software product quality," in Software Engineering and Applications (SEA 2003), M. Hamza, Ed. Acta Press, 2003.

[34] Moore, James W. Software engineering standards: a user's road map. IEEE Computer Science Press, Los Alamitos, California, 1998,

[35] ISO/IEC JTC1/SC7, New Work Item Proposal: The application of conformity assessment methodology to process capability and organizational maturity, 07N4132, 8 August 2008.

[36] Dorling, Alec, "The Role of Process Standards in Automotive Systems Development," compsac, pp.1037-1038, 2008 32nd Annual IEEE International Computer Software and Applications Conference, 2008 